Психология. Журнал Высшей школы экономики,

2020. T. 17. № 4. C. 617-629. DOI: 10.17323/1813-8918-2020-4-617-629

\title{
НА ПУТИ К ЦЕЛОСТНОМУ ВИДЕНИЮ ЧЕЛОВЕКА
}

\author{
Д.В. УШАКОВ ${ }^{\mathrm{a}, \mathrm{b}}$ \\ ${ }^{a}$ ФГБУН «Институт психологии РАН», 129366, Москва, ул. Ярославская, д. 13, к. 1 \\ ${ }^{b}$ Московский государственный университет имени М.В. Ломоносова, 119991, Россия, Москва, \\ Ленинские горы, 1
}

\section{Резюме}

Ситуация психологии сегодня достаточно радикально меняется в связи с возникновением новых сложных задачи. Одна группа этих задач лежит в области макропсихологии - изучения состояния больших групп людей, таких как страны и регионы. На повестке дня стоят оценка психологического состояния общества, прогнозирование его изменения под влиянием различных факторов, изучение воздействия на экономику и т.д. Другую группу задач ставит развитие искусственного интеллекта и формирование больших данных. Здесь возникают вопросы использования больших данных для оценки психологических процессов, создания умных устройств для улучшения психологического состояния людей, поддержки и индивидуализации обучения и т.д. Остаются нерешенными и более старые задачи - создание теоретико-экспериментальной базы для психотерапевтической и консультационной практики. Решать все эти задачи для современной психологической науки непросто. Причина заключается в «фасеточном» характере психологической теории, где существует множество не связанных между собой моделей процессов, свойств, состояний, но отсутствует целостное видение психики человека. Я.А. Пономарев обозначил такое состояние знания термином «эмпирическая многоаспектность». Он предложил программу построения психологической теории, позволяющей синтезировать отдельные модели психических явлений в целостную конструкцию. Основу такого синтеза составляет структурно-уровневый подход, опирающийся на эволюционную теорию. Сегодня в области психологической теории можно наблюдать движение в сторону реализации программы Я.А. Пономарева. Активно развивается и приобретает центральное методологическое значение эволюционная проблематика. Происходит рефлексия локальных моделей с целью обнаружения того общего, что может выступить основой интеграции. Реализация этой программы и возникновение интегративной психологической теории на месте разрозненных фасеток будет означать выход психологии на новый уровень как в решении практических задач, так и в мировоззренческом значении - формировании образа человека и его места в мире.

Ключевые слова: эволюционизм в психологии, макропсихология, большие данные, эмпирическая многоаспектность, действенно-преобразующее знание.

Психология сегодня стоит перед задачами освоения новых теоретических и практических областей, связанных в первую очередь с развитием искусственного интеллекта, формированием больших данных и углублением макропсихологической проблематики. Старыми методами эти задачи решить не удается, однако потенциал формирования нового инструментария, опирающийся на глубокие методологические разработки, у нашей науки высок. Среди этих разработок особое место занимает подход, предложенный Я.А. Пономаревым.

Работа выполнена при поддержке РНФ, проект № 17-78-30035. 
Яков Александрович Пономарев вступил в науку в конце 1940-х - начале 1950-х гг. вместе с плеядой ученых, которым предстояло дать лицо позднесоветской психологии, и решал задачи, стоявшие в то время перед психологией. Однако при этом он сумел настолько глубоко заглянуть в основы психологического знания, что, как сегодня выясняется, совершенно новые для психологии проблемы могут плодотворно опираться на выработанную им методологию.

Ниже мы постараемся вычленить ряд периодов развития отечественной психологии и охарактеризовать основные существенные и специфические для этих периодов проблемы. Наибольший интерес, конечно, будут представлять проблемы, которые только начинают вставать перед психологией и которые будут, вероятно, наиболее значимыми в ближайшее десятилетие. Далее будет показано, каким образом методология Я.А. Пономарева дает ключ к этим проблемам.

На момент вступления Я.А. Пономарева в науку предшествующим поколением психологов были предложены пути построения способной к позитивному развитию психологии в условиях господства в стране марксистской идеологии (Ананьев, 1969; Выготский, 1999; Леонтьев, 1979; Рубинштейн, 1989). Надо отдать должное этому поколению в том, что не была допущена «лысенковщина» в психологии. Были проведены творческая переработка марксистской проблематики и ее наложение на область психологии. Благодаря этому отечественная психология вышла в лидеры в некоторых областях, таких, например, как проблема социальной и культурной обусловленности психики.

На этом фоне в годы активного вступления в науку поколения, к которому принадлежал Я.А. Пономарев, начался новый период развития отечественной психологии, для которого, пожалуй, важнейшей из задач стало создание теорий среднего уровня. Слово «средний» в определении уровня не должно вводить в заблуждение: это наиболее высокий уровень, на котором теория еще является «фальсифицируемой» (Поппер, 1983), далее на мировоззренческом уровне вступают в действие иные факторы принятия или выбраковки теории. Теории среднего уровня строятся на базе обширной фактологии, это не одиндва эксперимента, а целая область, разработанная сообществом исследователей за многие годы, а скорее - десятилетия (Журавлев, Ушаков, 2006).

Я.А. Пономарев, являясь в целом ярким представителем этого поколения психологов, все же занял в нем особое место. Он выступил автором ряда очень серьезных теорий среднего уровня, позволивших объяснить закономерности в области творчества, развития интеллекта, памяти (запоминание побочного продукта) и т.д. Он был остроумным и изобретательным экспериментатором, получившим новые факты. И то и другое - особенности наиболее блестящих представителей его возрастной когорты. Однако, помимо этого, он достиг выдающихся результатов в области методологии, которые далеко вышли за рамки этого этапа и начинают раскрывать свой потенциал в полной мере только в наши дни.

Постепенное развитие позднесоветской психологии было революционно нарушено в 1990-е гг. Это время можно считать рубежным для начала нового периода со своим кругом задач. Крушение Советского Союза Яков Александрович встретил уже в семидесятилетнем возрасте. Его деятельность связана, конечно, в первую очередь с предыдущим периодом. Тем не менее его подходы 
оказывались удивительно адекватны для решения новых проблем, которые стали выкристаллизовываться с течением времени. Охарактеризуем эти проблемы.

В «лихие девяностые» российская наука оказалась на голодном пайке. Началась миграция молодежи из науки. Миграция как внешняя - в зарубежные университеты, так и внутренняя - в более доходные области научной и околонаучной практики или вообще ненаучной деятельности. Задача как-то сохранить науку, сберечь кадры дополнялась, однако, рядом интересных содержательных проблем. Укажем лишь на некоторые из них.

Во-первых, идеологические требования окончательно рухнули, марксизм перестал быть обязательной основой, и встал вопрос об отношении к классическому советскому психологическому наследию. Надо было определить, что составляет пережиток тяжелого идеологического прошлого, а что - завоеванная в этом прошлом золотая крупица подлинной науки.

Во-вторых, произошло открытие вовне, российские ученые получили ограниченную лишь финансами возможность зарубежных стажировок и поездок на международные конференции. Иностранные ученые стали частыми гостями в России. Соответственно встал вопрос о соотношении шкал ценностей, заимствовании наиболее ценного из зарубежной психологии. Таким наиболее ценным, вероятно, оказался опыт проведения точных исследований, математической обработки данных и т.д.

В-третьих, стал складываться платежеспособный спрос на консультирование и психотерапию, что привело к бурному росту сообщества практических психологов. И тут стали выясняться неожиданные вещи. Оказалось, что вопреки идеальной картине советского времени теория, эксперимент и практика не образуют гармоничного единства. Обнаружился отрыв консультационной и психотерапевтической практики от психологического эксперимента. Появились яркие работы Ф.Е. Василюка и А.В. Юревича, которые утверждали, что в психологии теория не практична, а в психологическом сообществе существует «схизис»- академическое сообщество не знает практиков и наоборот (Василюк, 1996; Юревич, 2000).

Если две первые проблемы - специфически российские - нашли в прошедшие десятилетия свое более или менее успешное решение, то третья интернациональная по своей сущности - остается нерешенной во всем мире.

Сегодня четко складывается ощущение перехода к новому периоду развития нашей науки, контуры которого еще не вполне определенны, но уже понятно, что замаячили ориентиры, которых не было раньше. Ощущение перехода к новому периоду оказывается одновременно радостным и пугающим. Радостным - поскольку на психологию явно растет спрос, перед ней ставятся новые интересные вопросы. Пугающим - поскольку остается не вполне ясным, способны ли психологи удовлетворительно отвечать на эти вопросы.

Один из таких радостно-пугающих вопросов лежит в области, которую А.В. Юревич обозначил как макропсихология. Макропсихология - это психология больших групп людей, стран, регионов. По мере увеличения потребности в научной поддержке управления обществом стала выясняться очень важная тенденция: к психологам появился большой запрос не только на работу с 
одними отдельными людьми, но и на работу с психологическим состоянием общества (Юревич и др., 2007). Наиболее горячий пример на момент написания этой статьи - пандемия коронавируса. Перед психологами встают вопросы: как изменится психологическое состояние различных групп людей, если продлить карантин, принять те или иные карантинные меры? Как это скажется, например, на семейных отношениях или на политической ситуации? Эти вопросы крайне важны, но никто не может ответить на них, помимо психологов. Но могут ли ответить психологи?

Перед макропсихологией стоят и другие серьезные проблемы. Например, в одних лишь экономических терминах трудно объяснить, почему переходный период 1990-х гг. не сделал Россию такой же процветающей экономикой, как Германия, Франция или Великобритания, хотя была сделана попытка ввести аналогичные социально-экономические институты. Очевидно, большую роль сыграли менталитет населения и его влияние на жизнь общества и экономику. Этот столь важный для жизни вопрос также адресуется макропсихологии.

Интерес общества к макропсихологическим проблемам не может не вызывать у психологов ощущения значимости их науки для общества. Однако он и тревожит: можем ли мы дать ясные и точные ответы на задаваемые нам столь сложные вопросы? Можем ли мы, например, оценить объем карантинных мер, который допустим без тяжелых последствий для психологического состояния разных групп населения, роста психосоматических заболеваний или повышения конфликтности в семьях? Можем ли рекомендовать оптимальные институциональные формы с учетом менталитета тех или иных групп населения?

Особенность этих вопросов в том, что они требуют целостных моделей человека и групп людей, а эмпирическая база для таких моделей далеко выходит за рамки лабораторий. Более того, здесь встают задачи междисциплинарного характера, которые связаны с синтезом модели общества и модели человека, с математическим моделированием и обработкой больших данных. Все это создает тревожное ощущение, что требуется новый уровень психологической теории, но пути выхода на него не очень ясны.

Встает и еще одна группа задач. Она связана с появлением новых информационных технологий. Увеличение вычислительных мощностей и развитие технологий, в особенности - нейросетей глубокого обучения, привели к появлению устройств, которые способны распознавать паттерны и управлять сложными системами на уровне, а иногда и лучше человека. Из этого для психологов проистекает несколько практических следствий.

Может развиваться направление конструирования устройств, направленных на улучшение психологического состояния человека. Так, сегодня на повестке дня стоит вопрос создания диалоговых психотерапевтических систем. Реально создание систем искусственного интеллекта, помогающих в образовательном процессе: распознающих состояния учеников, а также предлагающих индивидуальные образовательные траектории. Эти примеры легко умножить. С.Ю. Степанов и Д.В. Ушаков предложили понятие индивидуальных цифровых ангелов для обозначения персонализированных технологий искусственного интеллекта, помогающих человеку в решении его личных жизненных задач. 
Но почему же тогда таких устройств или приложений пока на рынке не видно? По очень простой причине: психологическая теория на это пока не настроена.

Другая важная для психологии сторона развития интеллектуальных систем связана с тем, что современные устройства искусственного интеллекта успешно управляют сложными системами, например транспортом - самолетами, автомобилями. Это выводит на новый уровень проблематику инженерной психологии, где нужно моделировать взаимодействие человека не просто с объектами, состояние которых транслируется через приборные шкалы, а с такими системами, которые сами принимают решение об управлении на основе сбора информации и ее интеллектуальной переработки.

Новые технологии означают для психологов и возможность работы с большими данными. Сегодня используется, например, извлечение больших данных из соцсетей, где разворачивается небезынтересная социальная динамика. К. Маркс в свое время говорил, что экономика есть чувственно представшая психология людей. Сегодня можно сказать то же самое про соцсети, хотя, возможно, это суждение более поверхностно, чем марксово. Источники больших данных постоянно нарастают. Так, Федеральная резервная система США в настоящее время собирает информацию о работе всех кассовых аппаратов США. Это означает, что сегодня есть возможность получать информацию о всех покупках в огромной стране в реальном времени. Это ведь тоже чувственно представший аспект психологии людей.

Однако возникает большой вопрос: как с этими данными работать? И это вопрос не о математических или информационных методах обработки больших цифровых массивов. Вопрос - о психологических моделях, которые могут верифицироваться с помощью этих больших данных. В настоящее время используется стратегия проверки с помощью больших данных моделей, которые исходно созданы на основе экспериментов. Например, на материале компьютерных игр в Интернете были проверены модели научения.

Это, безусловно, полезное использование больших данных. Но дело в том, что большие данные отражают такие процессы, которые по своим масштабам заведомо превосходят то, что могут описать традиционные психологические модели. Возьмем, например, те же дискуссии в социальных сетях по злободневным вопросам. Психология хорошо поработала с проблемой воздействия, но на локальных интервалах времени и содержания. Мы неплохо понимаем, как в течение сорокаминутного эксперимента повлиять на мнение испытуемого по поводу вреда курения. Однако мы плохо понимаем, как изменяется вся многосложная система установок и убеждений групп людей на протяжении недель, месяцев и лет. Для такого исследования в лабораториях просто никогда не было условий. Между тем большие данные в соцсетях открывают нам именно такую возможность: мы можем наблюдать за высказываниями многих людей на протяжении значительных периодов времени. В этот момент оказывается, что существующие теоретические подходы работают здесь не очень хорошо. У нас нет моделей, которые могли бы описать изменение системы установок человека в ее целостности. Вновь складывается противоречие между серьезным запросом практики и возможностями теоретической психологии. 
Я.А. Пономарев не успел столкнуться с большинством описанных выше проблем, однако он сумел заранее обнаружить их корень, выразив это словосочетанием «эмпирическая многоаспектность знания». Эмпирическая многоаспектность - результат сочетания огромной сложности объектов, которыми занимается психология, и «конвейерного» способа производства психологического знания. Фактически современный психологический «мейнстрим» порожден в американских университетах, где было налажено производство психологического знания таким образом, что формулируются гипотезы, которые проверяются в строго контролируемых условиях.

Сейчас это кажется само собой разумеющимся, но не всегда таким было. До американской в психологии господствовала немецкая наука, которая действовала по-другому. В большой степени немецкая психология была интроспективной, а значит, там вообще не было данных, пригодных к воспроизведению вне интерпретации экспериментатора. Но даже в тех исследованиях, где регистрировалось поведение, в большинстве случаев не было жесткого контроля, который бы позволял однозначно принимать или отвергать гипотезы. Например, в знаменитой книге В. Келера по интеллекту приматов нельзя найти ни одной сколько-нибудь проверенной по современным понятиям гипотезы. Такого рода работу сегодня просто невозможно опубликовать в солидном международном журнале, а между тем она содержит ценные идеи и оказала огромное влияние на последующую науку. Однако это влияние происходило на идейном уровне подобно тому, как это наблюдается в философии - без эмпирических гипотез, которые мог бы перепроверить и при случае отвергнуть другой исследователь.

Американская система производства научной психологии работает отлично в том плане, что допускает кумуляцию знаний'. Однако ей присущ один плохо устранимый дефект. Для того чтобы получить воспроизводимый феномен, человек должен быть «препарирован»: его следует поставить в такую ситуацию, где максимально сужен диапазон реагирования и проявляется тонкий срез его свойств, состояний и процессов.

В результате получается возможным создать модели, мало уступающие по уровню точности моделям естественных наук, но каждая из этих моделей, увы, описывает лишь один аспект из многоликого человеческого существа. В результате создается психология «фасеточного типа»: модели, описывающие поведение человека в ситуациях, так сказать, «в пробирке», оказываются не связанными между собой.

Я.А. Пономарев так характеризовал ситуацию: «Специфическая особенность эмпирического типа (знания. - Д.У.) состоит в том, что критерии, на

\footnotetext{
${ }^{1}$ Справедливости ради необходимо отметить, что и основы конвейерного способа производства были заложены в немецкой психологии. Великолепный образец - исследование Г. Эббингауза по забыванию, которое далеко пережило породившую его эпоху и прочно вошло в фактологическую базу когнитивной психологии. Психофизика Э. Вебера и Г. Фехнера также хорошо вписывается в конвейерный подход: хотя она ориентирована на оценку связи субъективных состояний с объективными, все же первые берутся только сквозь призму объективно фиксируемых суждений.
} 
основании которых выделяются различные стороны явления, субъективны. Количество таких критериев ничем не ограничено. В итоге множества исследований возникает то состояние рассматриваемой области, которое мы называем эмпирической многоаспектностью: огромная масса эмпирических работ становится необобщаемой; эта масса представляет конгломерат знаний, который захлестывает науку, лишая ее способности к обобщению...» (Пономарев, 1983, с. 41).

Это положение дел представлено на рисунке 1. На первом шаге производства психологического знания человек раскладывается на множество модельных ситуаций, затем для поведения в каждой из модельных ситуаций предлагаются свои, часто весьма точные и остроумные теории (рисунок 1А). Однако эти теории не связаны между собой, «необобщаемы», в терминах Я.А. Пономарева, и формируют фасеточный образ человека, подобный глазу насекомого (рисунок 1Б).

Если теперь вернуться к описанным выше актуальным проблемам психологии, то можно увидеть, что именно в «фасеточности», отсутствии целостного ви́дения человека лежит их корень. В самом деле, там, где для практики требуется изолировать отдельные свойства человека, например, способность человека перерабатывать информацию от индикаторов, психология прекрасно справляется со своими задачами, активируя соответствующие фасетки знаний. Но там, где требуется целостное понимание человека, будь то в консультационной или психотерапевтической практике или в анализе событий в соцсетях, сказывается отсутствие целостного ви́дения человека.

Я.А. Пономарев не только поставил диагноз теоретической психологии, который сегодня выглядит еще более актуальным и еще более объясняющим болевые точки науки и научно-технологической практики, чем 40 лет назад.

Рисунок 1

Современное психологического знание. А - «американская» схема производства психологического знания; Б - фасеточный глаз насекомого как метафора психологического знания, состоящего из множества несвязанных частей

A

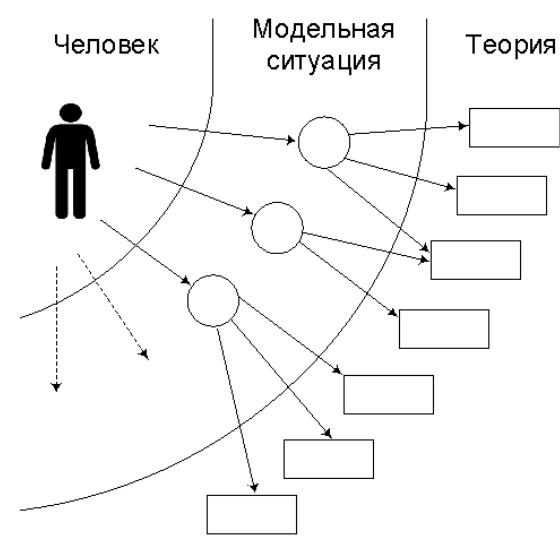

Б

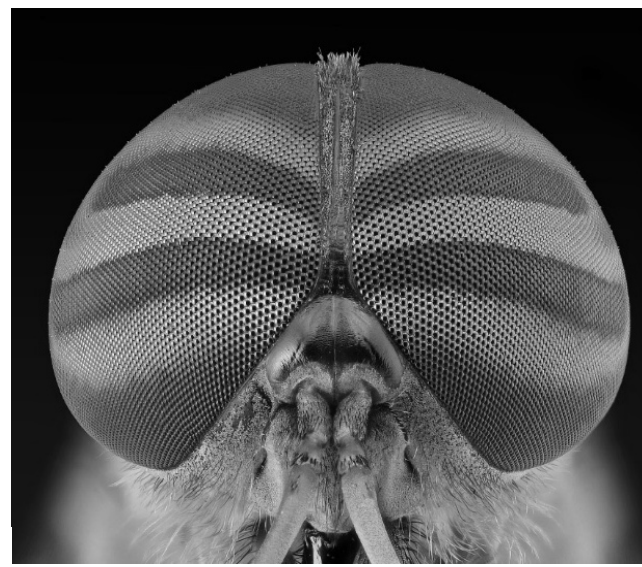


Он еще и предложил способ лечения. Очевидно, что это лечение должно привести к появлению синтетических моделей, которые бы позволяли объяснять и предсказывать поведение человека в широком спектре ситуаций. Но как этого достичь?

Движение в науке в сторону формирования теорий, синтезирующих то, что существовало ранее, действительно происходит. Так, например, теория относительности фактически позволила свести к единой объяснительной схеме феномены классической механики и максвелловской электродинамики, до того объяснявшиеся каждые своей моделью (Ушаков, 2005).

Однако сказать, что объединение происходит за счет обобщения существующих моделей, значит упустить главное. На примере той же теории относительности можно показать, что обобщение частных моделей в общие - это не алгоритм по типу создания более общей категории, соединяющей частные, а глубоко творческий процесс открытия нового ви́дения явлений и многомерного представления того, что до этого казалось не связанными между собой плоскостями. Движение к теории относительности началось с глубокой рефлексии оснований и основополагающих принципов электродинамики, которое вылилось в формулировку преобразования Лоренца (Г. Лоренц, А. Пуанкаре). Это создало возможность переноса отрефлектированных принципов на область механики (А. Пуанкаре, А. Эйнштейн).

Обобщенная модель меняет всю систему понятий науки, недаром для Т. Куна переход к теории относительности - классический пример смены парадигм. Отсюда становится понятным, что призывать к обобщению моделей означает не сказать ничего конкретного. Это равносильно тому, чтобы призвать ученых быть творческими. Требуется новая картина мира, но откуда она может прийти?

Я.А. Пономарев наметил двоякий путь синтеза. Одно направление связано с путем эмпирического синтеза. Подметив сходство между поведением людей в разные моменты решения творческих задач и детей на разных этапах онтогенетического развития, он выдвинул принцип «этапы-уровни-ступени». Согласно этому принципу, этапы онтогенеза преобразуются в структурные уровни организации психологического механизма деятельности, которые проявляются на разных ступенях решения творческих задач.

Этот путь в определенном смысле подобен тому, что был пройден физиками при создании теории относительности: выделяется базовый принцип, который позволяет установить общее между несвязанными до того теориями. Если в физике базовый синтетический принцип, формулируемый в виде преобразования Лоренца, был открыт сначала в одной из областей - электродинамике, а затем перенесен на другую - механику, то в теории Я.А. Пономарева вначале отдельно, на различных эмпирических данных было проведено описание этапов онтогенетического развития интеллекта (способности действовать в уме) и ступеней решения творческих задач, а затем было осознано структурное сходство этих описаний, что привело к формулировке синтезирующего начала - принципа «этапы-уровни-ступени».

Однако параллельно Я.А. Пономарев намечает и другой путь, который связан с обозначением априорной синтезирующей рамки. Но откуда берется 
априорность? Ведь психология - эмпирическая наука, ее выводы основываются на фактах. Как мы можем предположить о психике что-то достоверно необходимое до получения каких-либо фактов? Как объяснить, почему человек устроен таким образом, а не другим? В принципе, конечно, ответить на этот вопрос очень сложно, поскольку для эмпирического изучения мы не имеем других разумных существ, кроме живущих на планете Земля. Если бы мы были психологами из некой распространенной по всему Космосу цивилизации, которая бы знала, что в районе альфа Центавры, например, живут другие разумные существа, которые обладают определенными свойствами или эмоциональными процессами, мы могли бы всерьез обсуждать, какими могут, а какими не могут быть психические процессы, свойства или состояния разумных существ. Поскольку мы этого не имеем, а имеем только одну жизнь и одно разумное существо, один вид разумного существа - человека, то мы эти вопросы можем ставить только в теоретической плоскости и, к сожалению, не можем переводить их в плоскость эмпирического изучения (Ушаков, 2018). Однако именно этот теоретический подход только и может дать основу для рефлексивного синтеза психологического знания по принципу «сверху вниз», поскольку он позволяет дедуцировать локальные модели из общих принципов организации.

Современное общенаучное ви́дение состоит в том, что люди с их психикой порождены эволюцией. Поэтому ответы Я.А. Пономарев ищет на пути анализа эволюции, причем не только биологической, но и социокультурной, анализа причин, по которым она порождает существа, обладающие психикой, различные структуры взаимодействия этих существ вплоть до социальных институтов и культуры и т.д.

Механизм развития он описывает как уровневый, где этапы эволюции превращаются в структурные уровни организации. При этом верхние уровни постепенно возникают и совершенствуются благодаря побочным продуктам, накапливаемым на нижележащих уровнях.

Заостряя, можно сказать, что у Я.А. Пономарева речь идет о гипотезе «вечного двигателя» эволюции. Мы хорошо знаем, что вечный двигатель, генерирующий энергию, невозможен. Но в случае эволюции речь идет о другом вечном двигателе - потребляющем энергию, но генерирующем все возрастающий порядок в определенной части Вселенной вопреки тенденции к повышению энтропии.

Мы не знаем, возможен ли такой вечный двигатель. Однако если он не существует, то жизнь и разум на Земле являются результатом маловероятной случайности.

Дарвиновский механизм изменчивости и отбора - начало описания этого вечного двигателя. Этот механизм указывает на возможность самодвижения живых систем в сторону усложнения структур, однако ничего не говорит о структурах, порождаемых в результате саморазвития. Да, выживают более приспособленные. Но как устроены эти более приспособленные? А.Н. Северцов утверждал, что психика - это адаптивный механизм, позволяющий приспосабливаться к быстро меняющимся факторам среды (Северцов, 1945). Тогда логично заключить, что появление и совершенствование психики 
является закономерным результатом работы двигателя эволюции. Однако и идея А.Н. Северцова ничего не говорит о том, как должна быть организована психика и в какую сторону происходит ее развитие.

Здесь Я.А. Пономарев смыкает два пути синтеза и предлагает свой эскиз механизма двигателя когнитивного развития, основанный на принципе «этапы-уровни-ступени». Выдвигая этот принцип, он впервые перекидывает мост между проблематикой эволюции и организацией психики. Тем самым структурно-уровневая организация выдвинута им в качестве априори устройства психики по той причине, что так работает механизм эволюции.

Характерная особенность научного творчества Я.А. Пономарева состоит в том, что методологическая линия у него шла параллельно и в сотрудничестве с конкретными психологическими исследованиями (Пономарев, 1976). Выделенные им структурные уровни и этапы онтогенетического развития, как было показано специальными исследованиями, при всем различии терминологии можно соотнести со стадиями умственного развития по Ж. Пиаже. Таким образом, два ученых параллельно и независимо друг от друга пришли к примерно одинаковым конкретным представлениям о структурно-уровневой организации человеческой психики.

Вернемся, однако, к проблемам сегодняшней психологии. Я.А. Пономарев фактически разработал фундаментальную программу развития психологии от разрозненной эмпирической многоаспектности к интегративной, или, как он выражался, «действенно-преобразующей». Можно отметить, что в ходе протекающих в настоящее время процессов фактически формируются элементы реализации этой программы. О некоторых из этих элементов речь шла выше.

Уже было сказано, что сформировался серьезный практический запрос на решение таких задач, которые под силу только интегративной психологической теории. У такой психологии уже есть потенциальные потребители и заказчики.

Образовались методы эмпирического тестирования интегративных моделей, которых раньше не было, - большие данные о реальном человеческом поведении. Ведь вырезание траншей из живой человеческой психики - не прихоть экспериментаторов, это необходимость в результате огромного превосходства в сложности психики по сравнению с экспериментальными ситуациями. В этом плане большие данные обещают дать эмпирическую основу для моделей новой психологии.

Однако есть и другие детали пазла программы Я.А. Пономарева. Активно развивается эволюционная проблематика в психологии, она приобретает центральное методологическое значение (Асмолов и др., 2017). Таким образом, формируется движение «сверху вниз»: от общих принципов к интеграции локальных моделей.

Есть и встречное движение «снизу вверх» - рефлексия локальных моделей с целью обнаружения того общего, что может выступить основой интеграции. Наиболее заметно оно, пожалуй, в области глобальных когнитивных моделей, где появляется подобие иерархии более общих и более частных моделей.

Безусловно, на пути реализации этой программы еще очень много трудностей. Та же работа с большими данными при всех оптимистических прогнозах и декларациях на практике движется не слишком быстро. 
Безусловно также, процесс реализации столь радикальной программы не может происходить без ее существенной трансформации и наполнения новыми смыслами. Более того, он предполагает серьезные перемены в организации труда исследователей-психологов. Это касается работы по эмпирической проверке моделей, которая будет опираться на сочетание лабораторных исследований и анализа данных поведения в реальной жизни. Но это касается и теоретической работы, которая должна будет связывать конкретные модели с общими и может в значительно большей степени, чем сейчас, подключить математическое моделирование.

Во всех случаях, однако, реализация этой программы - возникновение интегративной психологической теории на месте разрозненных фасеток будет означать выход психологии на новый уровень как в решении практических задач, так и в мировоззренческом значении - формировании образа человека и его места в мире. Такие теоретики, как Я.А. Пономарев, - конкурентное преимущество российской психологии. В столетний юбилей Якова Александровича нам важно помнить об этом и, вдохновляясь примером предшественников, развивать методологическую рефлексию, которая одна может быть противопоставлена грубой силе экстенсивных исследований.

\section{Литература}

Асмолов, А. Г., Шехтер, Е. Д., Черноризов, А. М. (2017). Преадаптация к неопределенности как стратегия навигации развивающихся систем: маршруты эволюции. Вопросы психологии, 4, 3-26.

Ананьев, Б. Г. (1969). Человек как предмет познания. Л.: Изд-во ЛГУ.

Василюк, Ф. Е. (1996). Методологический смысл психологического схизиса. Вопросы психологuи, 6, 25-40.

Выготский, Л. С. (1999). Мышление и речь. М.: Лабиринт.

Журавлев, А. Л., Ушаков, Д. В. (2006). Введение в издательскую серию «Научные школы ИП РАН». В кн. Д. В. Ушаков (ред.), Психология творчества: школа Я.А. Пономарева (с. 9-18). М.: Изд-во «Институт психологии РАН».

Леонтьев, А. Н. (1979). Деятельность. Сознание. Личность. М.: Политиздат.

Пономарев, Я. А. (1976). Психология творчества. М.: Наука.

Пономарев, Я. А. (1983). Методологическое введение в психологию. М.: Наука.

Поппер, К. (1983). Избранные работы. М.: Наука.

Рубинштейн, С. Л. (1989). Основь общей психологии. М.: Наука.

Северцов, А. Н. (1945). Собрание сочинений. М./Л.: Изд-во АН СССР.

Ушаков, Д. В. (2005). Системность в психологии интеллекта - теория, подход, методология. В кн. В. А. Барабанщиков (ред.), Идея системности в современной психологии (с. 236-261). М.: Изд-во «Институт психологии РАН».

Ушаков, Д. В. (2018). Анатомия психологического знания. В кн. А.Л. Журавлев, А. В. Юревич (ред.), Психологическое знание: Современное состояние и перспективы развития (с. 71-114). М.: Изд-во «Институт психологии РАН».

Юревич, А. В. (2000). Психология и методология. Психологический журнал, 21(5), 35-47. 
Юревич, А. В., Ушаков, Д. В., Цапенко, И. П. (2007). Оценка психологического состояния российского общества: количественный подход. Психологический журнал, 28(4), 23-34.

Ушаков Дмитрий Викторович - директор Института психологии РАН; заведующий кафедрой, кафедра общей психологии, факультет психологии МГУ им. М.В. Ломоносова, академик РАН, доктор психологических наук, профессор.

Сфера научных интересов: структурно-динамическая теория интеллекта, психология творчества и одаренности, социальный и эмоциональный интеллект, макропсихология, методологические проблемы психологии.

Контакты: ushakovdv@ipran.ru

\title{
Towards a Holistic Human Study
}

\author{
D.V. Ushakov ${ }^{\mathrm{a}}$
}

${ }^{a}$ Institute of Psychology, Russian Academy of Sciences, 13 build. 1, Yaroslavskaya Str., Moscow, 129366, Russian Federation

${ }^{b}$ Lomonosov Moscow State University, 1 Leninskie Gory, Moscow, 119991, Russian Federation

\begin{abstract}
Contemporary psychology is undergoing radical changes in response to the appearance of new, complex problems. One cluster of problems concerns macro-psychology, which concerns the study of large groups of people, such as regions and countries. This involves assessing society's psychological state, predicting its dynamics under the influence of various factors, and analyzing the attendant impacts on the economy. Another cluster of problems concerns AI and Big Data, as pertains to issues such as analyzing psychological processes, designing smart devices to improve mental wellbeing, and implementing individualized learning programs. There also remain many unsolved older problems, such as the creation of a theoretical-experimental basis for psychotherapeutic and consulting practice. It isn't easy for modern psychological science to find answers to all these problems. Part of the reason has to do with the multi-faceted nature of psychological theory, which contains a large number of unrelated models of processes, properties, and states, but lacks a holistic viewpoint of the human psyche. Yakov Ponomarev termed this epistemological state of affairs as "empirical multidimensionality". He proposed a pathway to a psychological theory that could allow psychologists to synthesize individual models of mental processes into a holistic construct, with a structural-level approach based on evolutionary theory constituting the foundation of such a synthesis. Today, there are movements towards an implementation of Ponomarev's program in psychological theory. Evolutionary approaches are developing and acquiring a central methodological significance. Local-scale models are being scrutinized in search of contact points for a broader integration. The implementation of this program - the creation of a unified psychological theory in place of the current patchwork of disparate models - could mark psychology's advancement to a new level not just as regards its capacity to solve practical problems, but to provision an overarching perspective on humanity and its place in the world.
\end{abstract}

Keywords: evolutionism in psychology, macropsychology, big data, empirical multidimensionality. 


\section{References}

Asmolov, A. G., Chernorizov, A. M., \& Shekhter, E. D. (2017). Preadaptatsiya k neopredelennosti kak strategiya navigatsii razvivayushchikhsya sistem: marshruty evolyutsii [Pre-adaptation to uncertainty as a strategy to navigate in developing systems: evolutionary paths]. Voprosy Psikhologii, 4, 3-26. (in Russian)

Ananiev, B. G. (1969). Chelovek kak predmet poznaniya [Human as a subject of knowledge]. Leningrad: Leningrad State University. (in Russian)

Vasilyuk, F. E. (1996). Metodologicheskii smysl psikhologicheskogo skhizisa [A methodological meaning of psychological schism]. Voprosy Psikhologii, 6, 25-40. (in Russian)

Vygotsky, L. S. (1999). Myshlenie i rech' [Thinking and speech]. Moscow: Labirint. (in Russian)

Zhuravlev, A. L., \& Ushakov, D. V. (2006). Vvedenie v izdatel'skuyu seriyu "Nauchnye shkoly IP RAN" [Introduction to a publishing series "Scientific schools in the Institute of Psychology of the Russian Academy of Sciences]. In D. V. Ushakov (Ed.), Psikhologiya tvorchestva: shola Ya.A. Ponomareva [The psychology of creativity: A school of Ya. A. Ponomarev] (pp. 9-18). Moscow: Institute of Psychology of the RAS. (in Russian)

Leontiev, A. N. (1979). Deyatel'nost'. Soznanie. Lichnost' [Activity. Consciousness. Personality]. Moscow: Politizdat. (in Russian)

Ponomarev, Ya. A. (1976). Psikhologiya tvorchestva [The psychology of creativity]. Moscow: Nauka. (in Russian)

Ponomarev, Ya. A. (1983). Metodologicheskoe vvedenie v psikhologiyu [A methodological introduction to psychology]. Moscow: Nauka. (in Russian)

Popper, K. (1983). Izbrannye raboty [Selected works]. Moscow: Nauka. (in Russian)

Rubinstein. S. L. (1989). Osnovy obshchei psikhologii [The principles of general psychology]. Moscow: Nauka. (in Russian)

Severtsov, A. N. (1945). Sobranie sochinenii [Collected writings]. Moscow/Leningrad: AN SSSR.

Ushakov, D. V. (2005). Sistemnost' v psikhologii intellekta - teoriya, podkhod, metodologiya [Complexity in psychology of intelligence - theory, approach, methodology]. In V. A. Barabanshchikov (Ed.), Ideya sistemnosti v sovremennoi psikhologii [The idea of complexity in contemporary psychology] (pp. 236-261). Moscow: Institute of Psychology of the RAS. (in Russian)

Ushakov, D. V. (2018). Anatomiya psikhologicheskogo znaniya [The anatomy of psychological knowledge]. In A. L. Zhuravlev \& A. V. Yurevich (Eds.), Psikhologicheskoe znanie: Sovremennoe sostoyanie i perspektivy razvitiya [Psychological knowledge: A contemporary state and perspectives of development] (pp. 71-114). Moscow: Institute of Psychology of the RAS. (in Russian)

Yurevich, A. V. (2000). Psikhologiya i metodologiya [Psychology and methodology]. Psikhologicheskii Zhurnal, 21(5), 35-47. (in Russian)

Yurevich, A. V., Uhakov, D. V., \& Tsapenko, I. P. (2007). Otsenka psikhologicheskogo sostoyaniya rossiiskogo obshchestva: kolichestvennyi podkhod [Evaluation of the psychological state of the Russian society: A quantitative approach]. Psikhologicheskii Zhurnal, 28(4), 23-34. (in Russian)

Dmitry V. Ushakov - Director, Institute of Psychology of Russian Academy of Sciences; Head of the Department, Department of Psychology, Lomonosov Moscow State University, Member of the Russian Academy of Sciences, D.Sc., Professor.

Research area: New Investment Theory of intelligence, creativity, giftedness, social and emotional intelligence, macropsychology, philosophy of psychology.

E-mail: ushakovdv@ipran.ru 